\title{
Anesthetic Challenges in Minimally Invasive Cardiac Surgery
}

\author{
Uma Balasubramanyam ${ }^{1}$ Poonam Malhotra Kapoor ${ }^{1}$ \\ ${ }^{1}$ Department of Cardiac Anaesthesia, Cardiothoracic Center, All \\ India Institute of Medical Sciences, New Delhi, India \\ Address for correspondence Poonam Malhotra Kapoor, MD, DNB, \\ MNAMS, FIACTA (Hony), FTEE (Hony), FISCU (Hony), Department of \\ Cardiac Anaesthesia, Cardiothoracic Center, All India Institute of Medical \\ Sciences, New Delhi, India (e-mail: drpoonamaiims@gmail.com).
}

J Card Crit Care TSS 2020;3:28-35

\section{Introduction}

The transition of cardiac surgery away from the traditional sternotomy approach toward more minimally invasive strategies continues to evolve over time. The advancements in endoscopic instruments with better visualization tools marked the progress of the minimally invasive approach during the 1990s. ${ }^{1}$ This was followed by the emergence of robotic era of surgical procedures. In 2002 the FDA approved the Da Vinci system of robots for use in cardiac surgery ${ }^{2}$ ( - Fig. 1 ).

Despite the great interest in these procedures, a consensus definition of minimally invasive cardiac surgeries (MICS) is still not available. Simplistically, MICS techniques can be divided into two groups: (a) beating heart cardiac surgery without $\mathrm{CPB}$ and (b) port-access cardiac surgery requiring video assistance and closed-chest $\mathrm{CPB} .{ }^{3}$ Vanermen ${ }^{4}$ defined four categories of less invasive cardiac surgery: (a) direct coronary artery surgery via sternotomy on the beating heart (no CPB); (b) limited or modified approaches using conventional techniques and instruments with either conventional CPB or the endovascular CPB (endoCPB) system; (c) minimally invasive direct coronary artery bypass on the beating heart via a parasternal or left anterior small thoracotomy; and (d) true port-access surgery, in which all surgical acts are performed through ports and the heart is arrested with the endoaortic clamp catheter.

published online

January 6, 2020
The robotic assisted cardiac surgery has developed dramatically in past two decades. Since its inception, RACS has found its role mainly in coronary artery bypass grafting (CABG) surgery, mitral valve repairs (MVR), and atrial septal defect (ASD) closures..$^{5-7}$ Of late, procedures such as maze procedure for atrial fibrillation, intracardiactumor resection, and some congenital heart surgeries such as patent ductusarteriosus (PDA) ligation and transatrial repair of tetralogy of Fallot have also been done with robotic assistance. Continued improvements in surgical telemanipulation systems and intelligent robotic-enhanced instruments have made it possible to perform RACSs with pinpoint precision.

These minimally invasive procedures offer several potential benefits in reducing overall morbidity (reduced postoperative pain, low rate of surgical site infection, reduced blood loss, and decreased need for transfusions) and provide greater patient satisfaction with early discharge and faster return to normal daily activities. Nonetheless, whether the supposed benefits of MICS translate into clinical favorable outcomes still remains controversial, and there are conflicting opinions about whether minimally invasive surgery is ready for routine uptake in place of conventional open surgery.

Anesthesiologists play in a key role in facilitating optimal outcomes in such procedures. Perioperative management of these patients poses specific challenges to the anesthesia

Copyright $\odot 2020$ Official Publication of The Simulation Society (TSS), accredited by International Society of Cardiovascular Ultrasound (ISCU).
License terms

(1) (1) $\Theta \circledast$ 10.1055/s-0039-3401464 ISSN 2457-0206. 


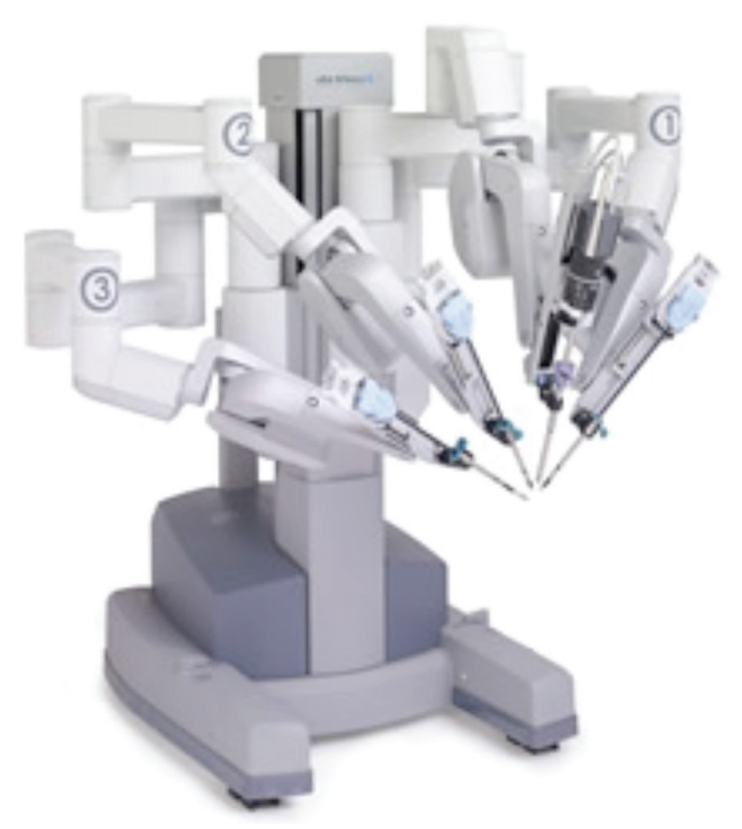

Fig. 1 Da Vinci robotic system.

team. The anesthesiologist must be skilled in numerous subspecialty skillsets including regional anesthesia and analgesia techniques, elements of thoracic anesthesia practice, in particular, one-lung ventilation (OLV), cardiac anesthesia, and transesophageal echocardiography (TEE). This review focuses on anesthetic considerations in MICS.

\section{History}

Minimally invasive cardiac surgery was invented by Dr. Joseph T McGinn, Jr. The first minimally invasive heart cardiac surgery was performed in the United States on January 21, 2005, at The Heart Institute at Staten Island University Hospital in Staten Island, New York, by a team led by Dr. Joseph T. McGinn. This technique was an off-pump coronary artery bypass surgery. In the mid-1990s, Cosgrove and Cohn independently described the first minimally invasive MVS (MIMVS). In 1996, Cosgrove and Sabik described approaching the aortic valve through a right parasternal incision with rib cartilage resection. ${ }^{8}$ Use of robots in cardiac surgeries started in 1998 when Carpentier et al performed the first robot-assisted MVR. ${ }^{9}$ Loulmet et al performed the world's first totally endoscopic robotic CABG (TECAB) in $1998 .{ }^{10}$

\section{Anesthetic Management}

Anesthesia for MICS and RACS requires a radical departure from the standard management protocol of cardiac surgery. It should be remembered that our goals of maintaining intraoperative hemodynamic stability stand true for these patients as well and the postoperative goals should focus on early/fast track extubation. General anesthesia remains the preferred technique with the need of OLV ventilation in most of the patients. However, many centers have reported successful outcomes with high thoracic epidural anesthesia on spontaneously breathing patients. ${ }^{11}$ Combined general anesthesia with thoracic epidural anesthesia can provide intraoperative hemodynamic stability with adequate postoperative analgesia. ${ }^{12}$

\section{Preanesthetic Evaluation}

Good and effective communication between the surgeon, anesthesiologist, perfusionist, and nurses is of utmost importance in the optimal outcome of these patients.

The next important step is appropriate patient selection. It is important in reducing the risk of perioperative complications. Endoscopic surgery is more difficult in smaller patients with insufficient thoracic space $(<3 \mathrm{~cm})$ or patients with body mass index of greater than $35 \mathrm{~kg} / \mathrm{m} .{ }^{2,12}$ Anatomical issues that hinder port placement, limit robotic arm movements, or reduce the already limited view within the thorax will increase the risk for surgical error and compromise patient safety. These include patients with prior thoracic surgery, external beam radiation to the chest, a history of thoracic trauma with chest tube insertion, or an enlarged or rotated heart, making the endoscopic procedure technically difficult and, thereby, putting the patient at higher risk.

If percutaneous cannulation is planned for $\mathrm{CPB}$, it is prudent to evaluate the vasculature for adequacy of flow, diameter, tortuosity, and the presence of atheromatous plaque. ${ }^{13}$ Assessment of peripheral pulses and computed tomography angiogram of the chest, abdomen, and pelvis will provide a detailed assessment of the thoracic and abdominal aorta as well as iliac and femoral vessels.

During totally endoscopic procedures with an arrested heart, an endoaortic balloon catheter is inserted percutaneously into the ascending aorta, and the balloon is inflated to occlude the ascending aorta. ${ }^{14}$ The heart is then arrested following administration of cardioplegia solution. A perioperative transesophageal echocardiography (TEE) should be performed to measure the size of the ascending aorta and confirm that it is $<3.8 \mathrm{~cm}$ to facilitate occlusion of the ascending aorta during administration of anterograde cardioplegia and minimize the risk of migration. ${ }^{15}$

Evaluation of the carotid arteries is prudent to stratify the patient's risk for stroke in the perioperative period. There has been an increased risk of vascular complications and stroke reported with peripheral arterial cannulation as compared with central access cannulation techniques. ${ }^{16}$

Patients undergoing MICS are candidates for OLV. They should be evaluated for history of chronic obstructive pulmonary disease (COPD), restrictive or infiltrative diseases of the lung, empyema, pleural effusions, or pulmonary hypertension. If suspected, they should be considered for additional pulmonary testing, including pulmonary function tests to determine lung capacity and whether an alternative approach may be better tolerated. Patients with mild COPD should be optimized with a course of bronchodilators and steroids prior to endoscopic heart surgery. Patients who smoke should be encouraged to stop at least 2 weeks prior to 
surgery. It has been demonstrated that patients with resting hypercarbia ( $>50 \mathrm{~mm} \mathrm{Hg}$ ), hypoxia $\left(\mathrm{PO}_{2}<65 \mathrm{~mm} \mathrm{Hg}\right.$ on room air), significantly lower forced vital capacity and forced expiratory volume in 1 second are unable to tolerate OLV and, thus, should not be considered for endoscopic procedures. ${ }^{17,18}$ Patients with unstable angina or recent myocardial infarction can have greater myocardial irritability and dysfunction in the setting of prolonged OLV. ${ }^{19}$

The anesthesiologist should review indices of left ventricular function, the patient's exercise tolerance, and the presence or absence of comorbid conditions. Patients with associated renal or hepatic insufficiency, previous cerebrovascular accidents, hematologic/coagulation disorders, or Jehovah's Witness faith (for whom blood transfusion is not an option) are ideal candidates for OPCAB.

\section{Preoperative Preparation and Premedication}

Laboratory evaluation is similar to that for conventional CABG surgery. However, hematology workup is often limited to a type and screen to limit costs, and patients are usually admitted on the same day of surgery. $\beta$-blockers such as atenolol may be administered for 1 or 2 days before surgery to aid in the control of perioperative tachycardia. Cardiac medications including $\beta$-blockers, statins, nitrates, and calcium channel blockers should be continued throughout the perioperative period. Angiotensin-converting enzyme (ACE) inhibitors should be omitted on the day of the surgery for postoperative prevention of hypotension. Antiplatelets such as clopidogrel should be stopped at least 5 to 7 days before surgery. Aspirin may be continued in the perioperative period. ${ }^{20}$

Patients should be kept fasting as per the American Society of Anesthesiologists fasting guidelines one night prior to surgery. ${ }^{21}$ Adequate sedation and anxiolysis is required for these patients to avoid catecholamine release. In our institution, we administer intramuscular inj morphine $0.01 \mathrm{mg} / \mathrm{kg}$ and injphenargan $0.5 \mathrm{mg} / \mathrm{kg}$ in this subset of patients.

\section{Monitoring}

Routine monitoring includes ECG, end-tidal $\mathrm{CO}_{2}$ concentration, pulse oximetry, CVP, invasive arterial pressure monitoring, temperature monitoring, bispectral index (BIS), and urine output.

Five-lead ECG monitoring is mandatory. However, sites of incision and port placement might preclude proper lateral chest lead placement of especially of V4 and V6 and thereby compromise on ischemia monitoring. Multiple modalities should be thus used for ischemia monitoring. One author with considerable experience in anesthetic management for MICS suggested that the most reliable measurement of myocardial function during the 7 to 10 minute distal coronary artery anastomosis is continuous cardiac output. ${ }^{3}$ Pulse-contour analysis and continuous thermodilution cardiac output measurements are two options available. ${ }^{22}$

Radial artery cannulation is the preferred approach. The planned use of an endovascular occlusion device (endoaortic occlusion balloon clamp [EAOBC]) in the ascending aorta requires continuous simultaneous monitoring of arterial catheters in the bilateral upper extremities (-Fig. 2).

The loss of a right sided arterial waveform may suggest that the endoaortic occlusion balloon catheter has migrated from the ascending aorta, obstructing the flow within the innominate artery. If a left upper extremity arterial line is contraindicated, or if the left axillary artery is used as an arterial cannulation site by the surgeon, a femoral arterial line should be used. An arterial line on the same side as the cannula would reflect line pressure instead of arterial blood pressure when the cannula is in use and, therefore, has limited hemodynamic significance.

Central venous cannulation should be inserted after discussing cannulation sites with surgeon. If superior vena cava (SCV) cannulation is planned (- Fig. 3), then left IJV will be ideal site for CVC. If there is associated coronary sinus cardioplegia delivery with SVC cannulation, then left femoral central venous catheters should be preferred. No attempt should be made to do puncture on both sides of the groin to place venous and arterial catheter for monitoring purposes.

PA catheterization is highly desirable as it not only helps in monitoring CO, PAP, CVP, and PCWP but also gives vital information about the peripheral oxygen delivery through $\mathrm{SvO}_{2}$ measurement. This becomes more informative with OLV.

TEE has a significant role in minimally invasive cardiac surgery to check the placement of various cannula as well as monitoring of myocardial ischemia and cardiac functions. Moreover, de-airing of the heart can be better monitored with TEE in view of the space constraint. It will be discussed in detail latter in this review.

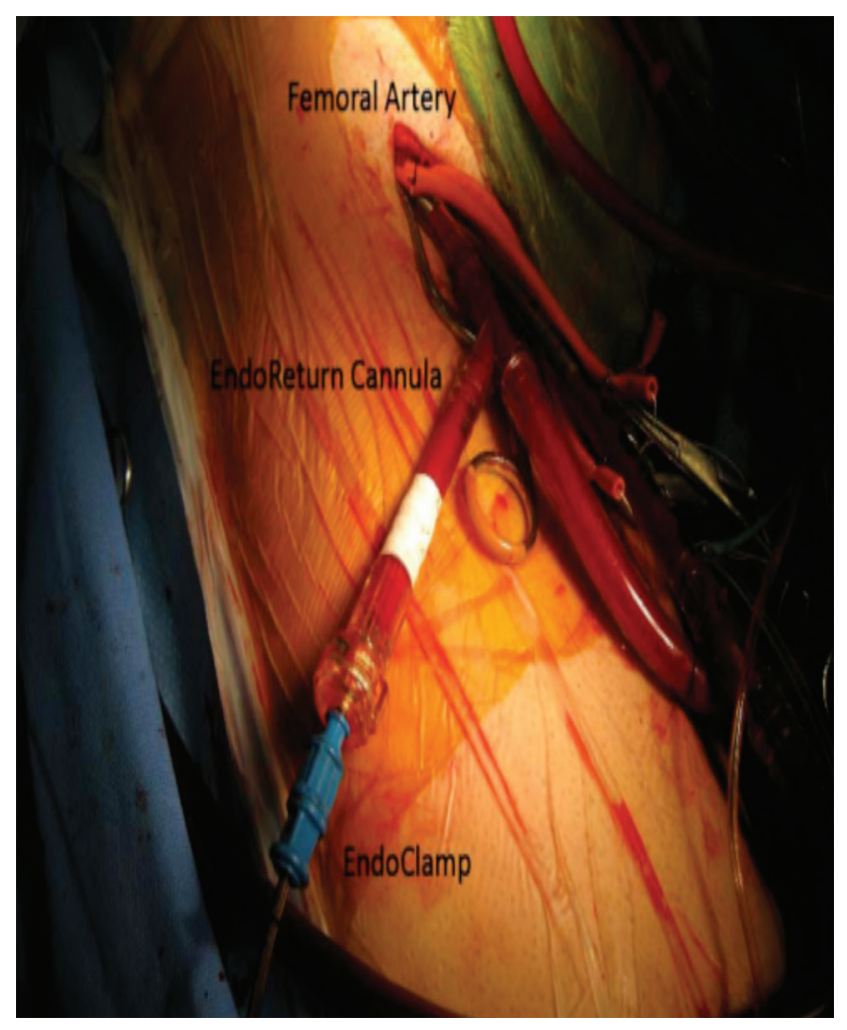

Fig. 2 Endoaortic balloon clamp-balloon-tipped catheter, inserted through the femoral artery positioned in the ascending aorta. 


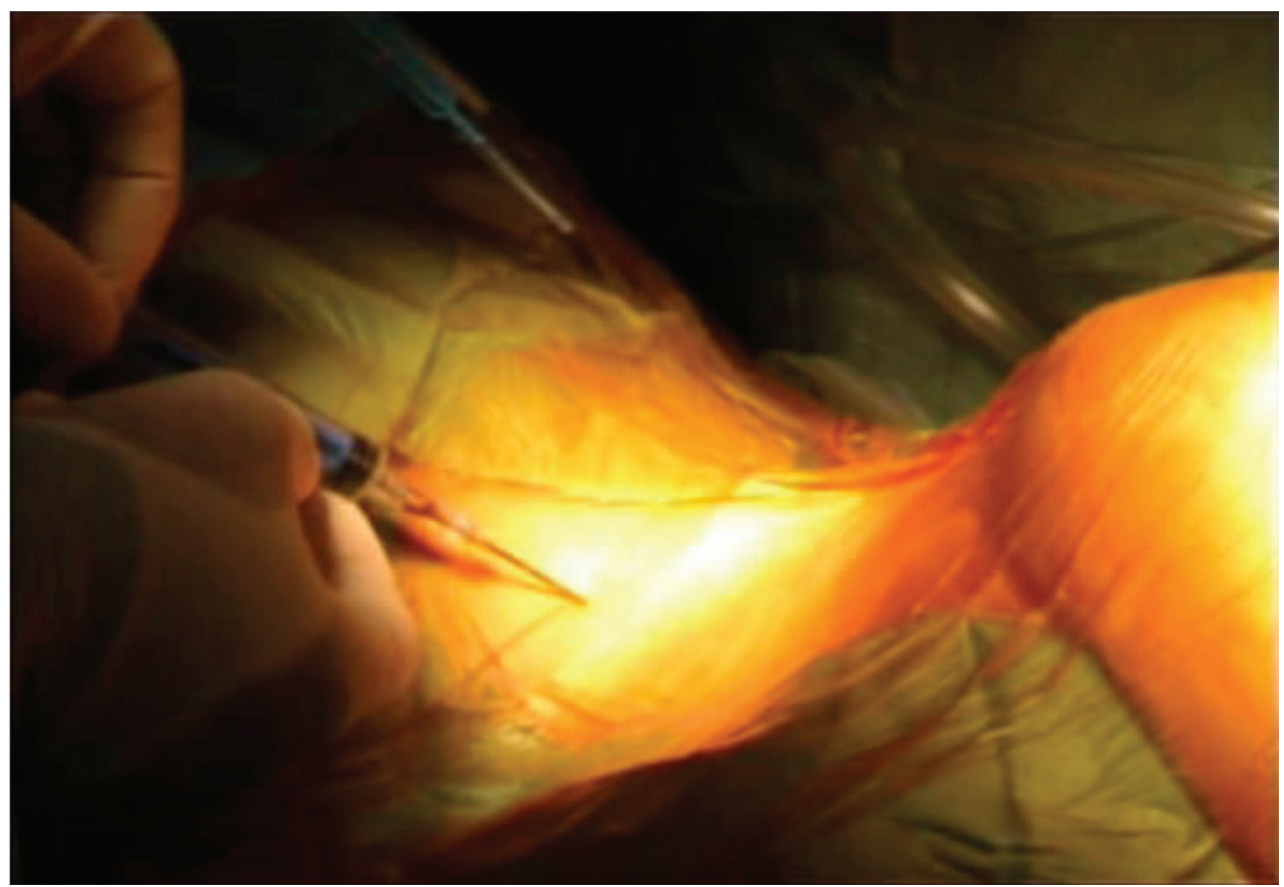

Fig. 3 SVC cannulation.

External defibrillator pads should be applied before the induction of anesthesia. Right coronary artery bypass by right minithoracotomy approach has been associated with bradycardia and atrioventricular conduction blocks; placement of pacing leads through the PAC should be considered.

Cerebral oximetry has been established as a noninvasive monitor of cerebral oxygenation in cardiac surgery. In minimally invasive and robotic heart surgery, cerebral oximetry is helpful in monitoring proper placement of the inflated EAOBC and may be the first indication of a technical problem or physiological change in the patient, which could potentially lead to an adverse outcome..$^{23}$ Any malposition of the $\mathrm{EAOBC}$ may cause a sudden decrease in the right-sided value, whereas a decline of the left-sided value may be due to occlusion of the left common carotid artery. A decline of $>20 \%$ in bilateral readings, with appropriate EAOBC positioning, should prompt stepwise assessments and interventions to optimize oxygen delivery to the brain. Such interventions may include increasing oxygen delivery via an increase in systemic blood pressure, $\mathrm{FiO}_{2}$, or hematocrit, as well as a decrease in cerebral metabolism such as increasing depth of anesthesia or decreasing systemic temperature. ${ }^{24}$

\section{Patient Positioning}

Patients are positioned supine with slight elevation of thorax and with a slight lateral tilt with the arm on the side of chest ports being suspended from a support at the level of the head. Proper arm positioning is crucial to prevent any inadvertent nerve plexus injury. However, patient should also be prepared for emergency sternotomy and thoracotomy as conversion to sternotomy may be required in 3 to $5 \%$ of patients. ${ }^{25}$ All pressure points should be padded and arterial and venous cannulae should be properly secured with long extension lines for drug and fluid administration.
The temperature in the operating room should be warm, and normothermia should be maintained. Warm-air blanket should be placed beneath the patient. Because CPB is not used, prophylactic anti-inflammatory and antifibrinolytic ( $\varepsilon$-aminocaproic acid [Amicar]) agents may not be administered.

\section{Induction of Anesthesia}

The anesthetic management goals of hemodynamic stability with controlled heart rate, and early emergence and extubation can be achieved by a wide variety of anesthetic techniques which is based on institutional protocols with considerable variation. Any balanced anesthetic technique that provides smooth induction and timely conditions for extubation can be used. Also, the type of procedure performed dictates the choice of induction agent as well as technique of anesthesia.

The practitioners of anesthesia for MICS/RACS propagate combined general and regional anesthesia. Various regional nerve blocks are used the commoner among which are the intercostal nerve block, the paravertebral block (PUB), thoracic epidural analgesia, and intrathecal opioid injection. Of these, thoracic paravertebral block (PVB) supplementing general anesthesia has been used in minimally invasive cardiac surgery. ${ }^{26}$ The advantage of PVB is minimal hemodynamic disturbance with no risk of epidural hematoma.

The induction agent can be either thiopentone or etomidate depending on cardiac disease involved following a small dose of inj fentanyl 3 to $5 \mu \mathrm{g} / \mathrm{kg}$. A "high-dose" regimen of fentanyl or sufentanyl that does not allow early emergence and extubation is not well suited for shorter-duration MICS procedures. The opioid remifentanil provides at least as good attenuation of the stress response in CABG patients, has little effect on myocardial contractility, and can be 
used safely in patients with decreased left ventricular function. ${ }^{27-29}$ It allows early tracheal extubation and may have a lower incidence of postoperative confusion. ${ }^{30}$ Total intravenous anesthesia (propofol/remifenantil) and inhalational anesthesia with supplemental intravenous opioids are anesthetic options. Because CPB is sometimes required, the use of nitrous oxide is omitted to avoid possible air embolism. ${ }^{31}$ muscle relaxation to facilitate endotracheal intubation is achieved with injrocuronium $1 \mathrm{mg} / \mathrm{kg}$. Pancuronium is best avoided due to its long duration of action albeit not contraindicated. ${ }^{32}$ The trachea is usually intubated with an appropriate sized left-sided double lumen tube (preferably left) ideally under fiberoptic visualization.

\section{One-Lung Ventilation}

Because MICS utilizes a right thoracotomy, lung isolation has been the mainstay of anesthetic management. The right lung is typically deflated as the surgeon enters the chest cavity and opens the pericardium to expose the left atrium before the initiation of СРB. One-lung ventilation (OLV) is also used at after separation from bypass as surgical sites are checked, bleeding is controlled, and the chest closed. However, OLV is not mandatory. The most common techniques for achieving lung isolation are with a left-sided double-lumen tube (DLT) or a right-sided bronchial blocker placed through a standard single-lumen endotracheal tube. The institution of OLV may create significant management difficulties in patients presenting for cardiac surgery. Any hypoxemia and hypercarbia during OLV will increase pulmonary vascular resistance (PVR) and cause additional strain on the right ventricle leading to RV dysfunction. Depressed cardiac function can further increase dead-space ventilation and limit pulmonary blood flow. Ventilation abnormalities may also lead to arrhythmias and may also be poorly tolerated, particularly in patients with marginal ventricular function.

The application of continuous positive airway pressure to the atelectatic lung and positive end expiratory pressure to the ventilated lung has been demonstrated to improve oxygenation. Other methods to improve oxygenation include increased $\mathrm{FiO}_{2}$, intermittent suctioning, recruitment maneuvers to ventilated lungs, partial ventilation of nonventilated lung, and so forth. In our center we advocate change of DLT to SLT prior to shifting the patient to cardiac intensive care unit.

Carbon dioxide insufflation poses additional challenges in a patient with OLV. Insufflation pressure is generally kept below $10 \mathrm{~mm}$ of $\mathrm{Hg}$, higher than $10 \mathrm{~mm}$ of $\mathrm{Hg}$ causes increase in intrathoracic pressure, decrease in venous return, cardiac output, and mixed venous oxygen saturation. This effect is accentuated in patients with compromised ventricular function. ${ }^{33}$ Increasing minute ventilation to compensate for the rise in $\mathrm{PaCO}_{2}$ may be difficult during OLV. Intrapleural pressure monitoring is essential during carbon dioxide insufflation to prevent pneumothorax and capnothorax and a pressure relief system should be in place to avoid hemodynamic collapse.

\section{Maintenance of Anesthesia}

Total intravenous anesthesia (propofol/remifenantil) and inhalational anesthesia with supplemental intravenous opioids are anesthetic options for maintenance. Heparin is administered before distal transection of the IMA and occlusion of the target coronary artery at a dose of 100 to $200 \mathrm{U} / \mathrm{kg}$ intravenously, with the end point for heparin monitoring being an activated clotting time (ACT) of at least $200 .{ }^{34}$

OPCABG requires a quite heart for coronary anastomosis. These can be achieved by pharmacologic, mechanical/physical, and "physiologic" methods. The pharmacologic methods include the following:

1. Esmolol, which decreases myocardial oxygen requirements, decreases heart rate, and may attenuate regional ischemia during vessel occlusion. ${ }^{35}$

2. Metoprolol, 0.5 to $1.0 \mathrm{mg}$ intravenously every 5 minutes titrated to a heart rate of 60 beats/minute, is an economical alternative to esmolol.

3. The calcium channel blockers diltiazem and verapamil can cause vasodilation and hypotension.

4. The induction of transient ventricular asystole with rapid bolus injection of adenosine $(0.2-0.3 \mathrm{mg} / \mathrm{kg})$ produces cardiac standstill lasting 5 to 12 seconds.

5. Persantine ( $5 \mathrm{mg}$ ) has been administered before occlusion of the target vessel to potentiate the effects of adenosine. ${ }^{36}$

6. Anticholinesterases such as neostigmine ${ }^{37}(0.5 \mathrm{mg}$ IV boluses) or edrophonium (5 mg IV boluses) can induce bradycardia without decreasing cardiac contractility.

7. A small dose of a short-acting opioid (remifentanil, sufentanil, and fentanyl) can also be effective in producing moderate slowing of the heart rate.

The use of pharmacologic stabilization combined with physical manipulation of the heart often results in a reduced cardiac index and systemic hypotension. A phenylephrine or norepinephrine infusion is occasionally necessary to maintain systemic blood pressure and augment coronary perfusion pressure during the coronary anastomosis.

Mechanical stabilization includes the following:

1. Occluding sutures.

2. Mechanical devices that reduce myocardial movement (Octopus 2, Medtronic; OPCAB Access Ultima System, Cardio Thoracic Systems). The Octopus stabilizer uses a series of suction cups on two fixed arms that allow adherence to the epicardium on either side of the target vessel. It provides excellent immobilization, limiting motion in an area of $\sim 1 \times 1 \mathrm{~mm}$ without compressing the heart, and allows mechanical traction for centering the site of anastomosis within the operative field. ${ }^{38}$

Apart from these, the anesthetist should be vigilant about hemodynamic changes occurring during cardiac manipulation requiring inotropic/chronotropic therapy or maneuvers to increase preload (e.g., Trendelenburg position). If extreme hemodynamic instability is encountered, placement of an IABP, institution of femoral-femoral bypass, use of a 


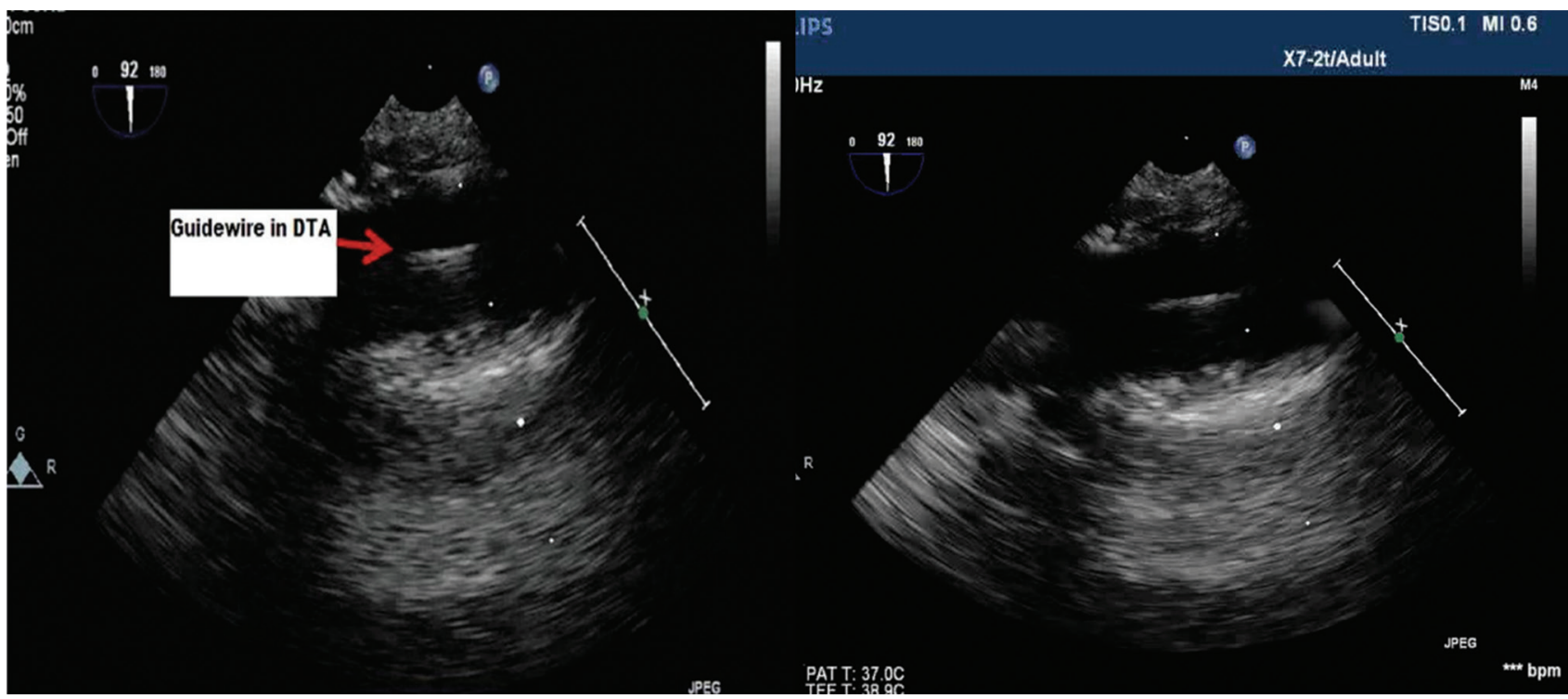

Fig. 4 Transesophageal echocardiography (TEE) upper esophageal long axis view showing femoral artery cannulation with the guidewire being visualized the descending aorta.

temporary coronary artery perfusion catheter, or conversion to traditional CABG with $\mathrm{CPB}$ may be required.

With completion of the coronary anastomosis, reperfusion is allowed. Reperfusion arrythmias may occur, especially if the native vessel was not severely occluded. Lidocaine $(1 \mathrm{mg} / \mathrm{kg})$ may be administered just before reperfusion in an attempt to reduce reperfusion dysrhythmias. Heparin is usually reversed with protamine but we usually avoid reversal with protamine at our institute and allow the residual heparin to be metabolized and its effect terminated over time.

Anastomotic quality is a critical issue in minimally invasive coronary surgery. Flow probes provide a continuous flow tracing and measurements of mean flow through the coronary graft. Flow through the coronary graft occurs during diastole, with a short systolic peak. Absence of diastolic flow in a graft is indicative of an occluded graft. In a graft that has some degree of stenosis, the flow is predominantly diastolic but with taller systolic peaks.

\section{TEE}

The practice of MICS/ RACS depends heavily on intraoperative TEE. In addition to precise delineation of pathology and evaluation of the surgical repair, TEE is used to detect additional findings that may impact the conduct of the operation. It not only aids in confirming the established diagnosis but is more important in aiding in cannulation and cardioplegia delivery system placement.

The need for real-time guidance during placement of guidewires and cannulae represents a unique role for TEE during robotic and minimally invasive cardiac surgery. During cannulation of the femoral artery, continuous TEE imaging ensures the successful guidewire passage into the descending aorta (-Fig. 4).

If the endoaortic balloon occlusion system is planned, TEE is further used to verify final balloon position $\sim 2 \mathrm{~cm}$ above the aortic root. Passage of a guidewire from the femoral vein during

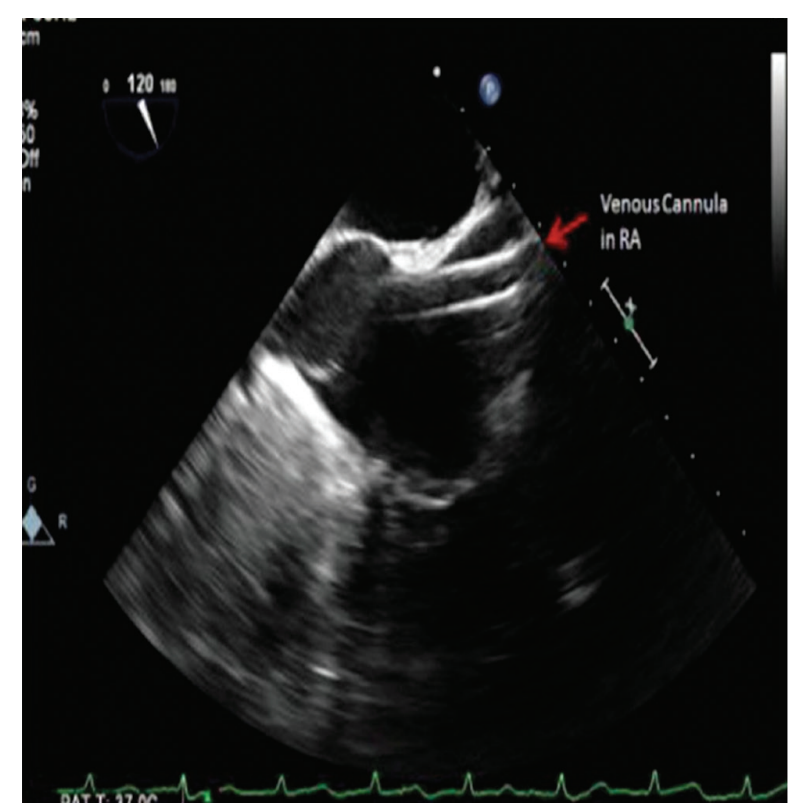

Fig. 5 Transesophageal echocardiography mid-esophageal bicaval view-SVC cannulation with tip of the guidewire visualized in RA.

venous cannulation is also monitored with TEE. Ideally the guidewire will pass through the RA ( - Fig. 5) and with the tip residing in the SVC.

Occasionally the femoral venous guidewire is malpositioned across a patent foramen ovale or becomes coiled in the RA appendage. The position of the guidewire and venous cannula introduced into the SVC from the RIJ are also monitored.

If percutaneous coronary sinus cannulation and placement of an endopulmonary vent are planned, TEE is also invaluable in confirming the positions of these devices as well. Both two-dimensional and three-dimensional TEE imaging may be used to visualize proper cannulation of the coronary sinus. The addition of color Doppler can verify flow 
of cardioplegia into the coronary sinus during CPB. Confirmation of proper location of an endopulmonary vent in the main pulmonary artery necessitates TEE imaging as well.

Once the procedure is done, the patient is weaned from $\mathrm{CPB}$. At this time, continuous TEE imaging is used to monitor air evacuation via the cardioplegia/vent line. The results of the valve repair / replacement, defects closed, ventricular function etc. are also assessed.

Real-time three-dimensional echocardiography may further provide adequate imaging and anatomic detail to act as an even better guide for surgical procedures. Further technological development is needed to minimize the transducer size and optimize the spatial resolution for the clinical setting.

\section{Conclusion}

Minimally invasive cardiac surgery keeps all in the operating room alert and extremely attentive. The challenges are many with less invasive surgery, the anaesthesiologist in the perioperative \& postoperative period is the key holder to patient's haemodynamic \& successful outcomes.

\section{Conflict of Interest}

None.

\section{References}

1 Clayman RV, Kavoussi LR, Soper NJ, et al. Laparoscopic nephrectomy: initial case report. J Urol 1991;146(2):278-282

2 Nifong LW, Chu VF, Bailey BM, et al. Robotic mitral valve repair: experience with the da Vinci system. Ann Thorac Surg 2003;75(2):438-442, discussion 443

3 Gayes JM. The minimally invasive cardiac surgery voyage. J Cardiothorac Vasc Anesth 1999;13(2):119-122

4 Vanermen $\mathrm{H}$. What is minimally invasive cardiac surgery? J Card Surg 1998;13(4):268-274

5 Sharma KK, Arora D, Mehta Y, Mishra Y, Wasir HS, Trehan $\mathrm{N}$. Peri-operative considerations in total endoscopic atrial septal defect repair with robotic assistance. Indian Heart J 2006;58(3):265-268

6 Mishra Y, Sharma M, Bapna R, et al. Minimally invasive mitral valve surgery. Indian Heart J 2002;54(3):279-283

7 Trehan N, Mishra YK, Sharma M, et al. Robotically controlled video-assisted port-access mitral valve surgery. Asian Cardiovasc Thorac Ann 2002;10(2):133-136

8 Cosgrove DM, III, Sabik JF, Navia JL. Minimally invasive valve operations. Ann Thorac Surg 1998;65(6):1535-1538, discussion 1538-1539

9 Carpentier A, Loulmet D, Aupècle B, et al. Computer assisted open heart surgery. First case operated on with success [in French]. C R Acad Sci III 1998;321(5):437-442

10 Loulmet D, Carpentier A, d'Attellis N, et al. Endoscopic coronary artery bypass grafting with the aid of robotic assisted instruments. J Thorac Cardiovasc Surg 1999;118(1):4-10

11 Kessler P, Neidhart G, Bremerich DH, et al. High thoracic epidural anesthesia for coronary artery bypass grafting using two different surgical approaches in conscious patients. Anesth Analg 2002;95(4):791-797

12 Seco M, Edelman JJ, Yan TD, Wilson MK, Bannon PG, Vallely MP. Systematic review of robotic-assisted, totally endoscopic coronary artery bypass grafting. Ann Cardiothorac Surg 2013;2(4):408-418
13 Feuchtner GM, Schachner T, Bonaros M, et al. Heart Surg Forum 2006;9:754-758

14 Anzai T, Iino Y, Kumeno T, Yozu R. Feasibility study of a direct endo-aortic clamp balloon. ASAIO J 2007;53(2):136-139

15 Deshpande SP, Lehr E, Odonkor P, et al. Anesthetic management of robotically assisted totally endoscopic coronary artery bypass surgery (TECAB) J Cardiothorac Vasc Anesth 2013;27(3):586-599

16 Iribarne A, Russo MJ, Easterwood R, et al. Minimally invasive versus sternotomy approach for mitral valve surgery: a propensity analysis. Ann Thorac Surg 2010;90(5):1471-1477, discussion 1477-1478

17 Murkin JM, Ganapathy S. Anesthesia for robotic heart surgery: an overview. Heart Surg Forum 2001;4(4):311-314

18 Lee JD, Srivastava M, Bonatti J. History and current status of robotic totally endoscopic coronary artery bypass. Circ J 2012;76(9):2058-2065

19 Srivastava S, Gadasalli S, Agusala M, et al. Beating heart totally endoscopic coronary artery bypass. Ann Thorac Surg 2010;89(6):1873-1879, discussion 1879-1880

20 Dunning J, Versteegh M, Fabbri A, et al; EACTS Audit and Guidelines Committee. Guideline on antiplatelet and anticoagulation management in cardiac surgery. Eur J Cardiothorac Surg 2008;34(1):73-92

21 Practice guidelines for preoperative fasting and the use of pharmacologic agents to reduce the risk of pulmonary aspiration: application to healthy patients undergoing elective procedures: an updated report by the American society of anaesthesiologists task force on preoperative fasting and the use of pharmacologic agents to reduce the risk of pulmonary aspiration. Anaesthesiology 2017;126(3):376-393

22 Buhre W, Weyland A, Kazmaier S, et al. Comparison of cardiac output assessed by pulse-contour analysis and thermodilution in patients undergoing minimally invasive direct coronary artery bypass grafting. J Cardiothorac Vasc Anesth 1999;13(4):437-440

23 Denault A, Deschamps A, Murkin JM. A proposed algorithm for the intraoperative use of cerebral near-infrared spectroscopy. Semin Cardiothorac Vasc Anesth 2007;11(4):274-281

24 Murkin JM, Adams SJ, Novick RJ, et al. Monitoring brain oxygen saturation during coronary bypass surgery: a randomized, prospective study. Anesth Analg 2007;104(1):51-58

25 Subramanian VA. Less invasive arterial CABG on a beating heart. Ann Thorac Surg 1997;63(6, Suppl):S68-S71

26 Mehta Y, Arora D, Sharma KK, Mishra Y, Wasir H, Trehan N. Comparison of continuous thoracic epidural and paravertebral block for postoperative analgesia after robotic-assisted coronary artery bypass surgery. Ann Card Anaesth 2008;11(2):91-96

27 Mollhoff T, Herregods L, Blake D, et al. Remifentanil versus fentanyl in patients undergoing CABG surgery. Anaesthesiology 1999;91:a144

28 Sprung J, Ogletree Hughes M, Moavec C. Effects of remifentanil on contractility of failing human ventricular muscle. Anaesthesiology 1999;91:a416

29 Larbuisson R, Van Dyck M, Herregods L, et al. Remifentanil is as well tolerated as fentanyl in patients with poor LV function during CABG surgery. Anaesthesiology 1999;91:a417

30 Möllhoff T, Herregods L, Moerman A, Blake D, MacAdams $C$ et al. Comparative efficacy and safety of remifentanil and fentanyl in 'fast track' coronary artery bypass graft surgery: a randomized, double-blind study. $\mathrm{Br} \mathrm{J}$ Anaesth 2001;87(5):718-726

31 Gayes JM, Emery RW, Nissen MD. Anesthetic considerations for patients undergoing minimally invasive coronary artery bypass surgery: mini-sternotomy and mini-thoracotomy approaches. J Cardiothorac Vasc Anesth 1996;10(4):531-535 
32 Maslow AD, Park KW, Pawlowski J, Haering JM, Cohn WE. Minimally invasive direct coronary artery bypass grafting: changes in anesthetic management and surgical procedure. J Cardiothorac Vasc Anesth 1999;13(4):417-423

33 Ohtsuka T, Imanaka K, Endoh M, et al. Hemodynamic effects of carbon dioxide insufflation under single-lung ventilation during thoracoscopy. Ann Thorac Surg 1999;68(1):29-32, discussion 32-33

34 Boonstra PW, Grandjean JG, Mariani MA. Improved method for direct coronary grafting without CPB via anterolateral small thoracotomy. Ann Thorac Surg 1997;63(2):567-569

35 Labovitz AJ, Barth C, Castello R, Ojile M, Kern MJ. Attenuation of myocardial ischemia during coronary occlusion by ultrashort-acting beta adrenergic blockade. Am Heart J 1991;121(5):1347-1352
36 Pawlowski J, Haering JM, Comunale ME, et al. Minimally invasive anesthesia should accompany minimally invasive surgery. J Cardiothorac Vasc Anesth 1997;11(4):536-537

37 Hesselvik JF, Ortega RA, Shemin RJ. The use of neostigmine to decrease the heart rate in a patient undergoing minimally invasive coronary artery bypass surgery. J Cardiothorac Vasc Anesth 1997;11(7):883-884

38 Borst C, Jansen EWL, Tulleken CAF, et al. Coronary artery bypass grafting without cardiopulmonary bypass and without interruption of native coronary flow using a novel anastomosis site restraining device ("Octopus") J Am Coll Cardiol 1996;27(6):1356-1364 